\title{
PROJETO CONCEITUAL DE APLICATIVO - PROPOSTA DE UMA TECNOLOGIA SOCIAL PARA AGRICULTORES FAMILIARES
}

Mara Rúbia da Silva Miranda (mara_miranda20@yahoo.com.br) - Universidade Federal de Goiás (UFG).

Maico Roris Severino (maicororis@ gmail.com) - Universidade Federal de Goiás (UFG).

Athanasios Rentizelas (athanasios.rentizelas@strath.ac.uk) - University of Strathclyde (UoS).

\section{RESUMO}

O Programa Nacional de Alimentação Escolar (PNAE) é um programa federal de compra pública de produtos alimentícios que dão prioridade à pequenos produtos rurais. No entanto, existem diversos entraves que impedem que agricultores familiares participem destes programas, visto que ainda enfrentam vários problemas ligados a produção e distribuição dos seus produtos, além da falta de conhecimento a tempo hábil dos editais do programa PNAE. Desta forma, uma demanda latente é o desenvolvimento de soluções que auxiliem o pequeno agricultor a enfrentar tais desafios. Neste contexto, o objetivo deste artigo é modelar funcionalmente um aplicativo como proposta de tecnologia social para um maior acesso dos agricultores familiares em chamadas do PNAE. Para tanto, por meio da pesquisa participante foram realizadas entrevistas e reuniões com um grupo de pequenos agricultores de um assentamento de reforma agrária para levantamento dos principais elementos para elaboração da modelagem funcional da tecnologia a ser desenvolvida. Dentre os principais achados destacam-se: a modelagem funcional de um aplicativo que permite a determinação do custo real de produção, o ranqueamento dos produtos por editais mais viáveis e propostas de roteamento. Este resultado permitirá no futuro a disponibilização de um aplicativo com tal função.

Palavras chave: projeto conceitual; aplicativo; agricultores; PNAE. 


\section{INTRODUÇÃO}

O Programa Nacional de Alimentação Escolar (PNAE), é uma política intersetorial que tem embasamento na Lei Federal $n^{\circ} 11.947$ aprovada em junho de 2009 e que passou a regulamentar a aquisição de produtos da agricultura familiar. Em seu artigo 14 é determinado que, do total de recursos financeiros repassados pelo Fundo Nacional de Desenvolvimento da Educação (FNDE) aos estados e municípios para gastos com a alimentação escolar, no mínimo 30\% devem ser utilizados na aquisição de gêneros alimentícios oriundos de agricultores familiares ou de suas organizações. A legislação também prevê que terão prioridade públicos específicos, como os assentados da reforma agrária, quilombolas e indígenas, os que produzem de forma orgânica/agroecológica e os organizados em cooperativas ou associações, nesta ordem. Desta forma, é possível trazer maior igualdade social a este público mais excluído dentro da população rural, além de reforçar a segurança alimentar e nutricional a partir da merenda escolar com produtos locais e agroecológicos.

O Brasil tem cerca de 1,5 milhão de pequenos agricultores locais (cerca de 350.000 famílias) que fazem parte do Movimento dos Trabalhadores Rurais Sem Terra (MST) e que poderia atender as chamadas do PNAE, porém, isso não acontece. No Brasil, o orçamento do PNAE vem aumentando ano a ano. Apesar desta possibilidade de os agricultores familiares, de modo especial de assentamentos de reforma agrária, obter uma garantia de renda por meio do PNAE, verifica-se que os agricultores não estão conseguindo participar destas chamadas de modo efetivo. Entre outros entraves, também se observa que atualmente os agricultores usam seus veículos privados para distribuição, sem qualquer planejamento padronizado, levando a eficiência reduzida, altos custos de entrega, perda de oportunidade de fornecimento de produtos, produtos não vendidos e qualidade reduzida dos produtos entregues devido à deterioração sensorial. Além disso, não conseguem analisar de modo eficaz quais chamadas públicas destes programas devem concorrer, já que desconhecem os custos de produção e os custos logísticos de todo o seu processo.

Neste sentido, o objetivo deste trabalho é modelar funcionalmente um aplicativo como proposta de tecnologia social para um maior acesso dos agricultores familiares em chamadas do PNAE. A proposta é ter um aplicativo onde as funções técnicas proporcionem o cálculo do custo logístico, o cálculo dos custos dos produtos, a otimização da rota para entrega dos produtos e que finalmente contribua na tomada de decisão para participar em uma chamada de um determinado edital. Para tanto, visando alcançar o objetivo geral, tem-se como objetivos 
específicos: Coletar dados com os agricultores familiares das necessidades quanto à proposta da tecnologia; Definir as especificações-meta que o aplicativo deverá atender; Definir a estrutura funcional do aplicativo, bem como suas funções técnicas e interativas; Definir a arquitetura do aplicativo através de esquemas que representem os elementos principais e suas interfaces; Descrever a concepção do produto final, mostrando os princípios de funcionamento do aplicativo e como a tecnologia satisfará as necessidades dos usuários.

Os sistemas e gerenciamento de produção e operações concentra-se em problemas de fluxo de produção e distribuição para grandes produtores industriais ou agrícolas. As especificidades do ambiente problemático para pequenos agricultores rurais, especialmente no que diz respeito ao conjunto de restrições de problemas, tornam este um problema único e complexo que exige soluções customizadas. Respostas como por exemplo, quais regiões serão mais rentáveis para se distribuir estes produtos ou ainda qual a maneira mais apropriada para essa distribuição, podem aumentar os lucros destes pequenos agricultores que até então desistem de suas atividades por não terem uma garantia do retorno. Estes fatores são de extrema importância para a melhor compreensão dos fatos reais e assim garantir que não haja desperdícios de recursos, e consequentemente garantir a eficiência de toda a cadeia produtiva, retorno financeiro para a comunidade, e, consequentemente, melhoria na qualidade de vida. É importante ressaltar que esta proposta se trata de uma demanda da comunidade do Assentamento Canudos, em que já há o comprometimento em termos de envolvimento da comunidade com a ação.

\section{REVISÃO TEÓRICA}

\subsection{Agricultura familiar e PNAE}

Segundo o Ministério da Agricultura, Pecuária e Abastecimento (MDA), a Lei 11.326/2006 diz que agricultores familiares são aqueles que praticam atividades no meio rural, possuem área de até quatro módulos fiscais, mão de obra da própria família e renda vinculada ao próprio estabelecimento e gerenciamento do estabelecimento ou empreendimento por parentes. Também entram nessa classificação silvicultores, aquicultores, extrativistas, pescadores, indígenas, quilombolas e assentados da reforma agrária.

Levantamento feito pelo portal Governo do Brasil mostra que a agricultura familiar tem um peso importante para a economia brasileira. Com um faturamento anual de US\$ 55,2 bilhões, 
caso o País tivesse só a produção familiar, ainda assim estaria entre os dez maiores produtores de alimentos. Os dados fazem parte de uma comparação entre dados do Banco Mundial e do Ministério da Agricultura, Pecuária e Abastecimento. Quando se soma a agricultura familiar com toda a produção, o Brasil passa de oitavo maior para a quinta posição, com faturamento de US\$ 84,6 bilhões por ano.

De acordo com o último Censo Agropecuário, a agricultura familiar é a base da economia de 90\% dos municípios brasileiros com até 20 mil habitantes. Além disso, é responsável pela renda de $40 \%$ da população economicamente ativa do País e por mais de $70 \%$ dos brasileiros ocupados no campo.

A Lei n ${ }^{\circ} 11.947$, de 16 de junho de 2009, determina que no mínimo $30 \%$ do valor repassado a estados, municípios e Distrito Federal pelo Fundo Nacional de Desenvolvimento da Educação (FNDE) para o PNAE deve ser utilizado na compra de gêneros alimentícios diretamente da agricultura familiar e do empreendedor familiar rural ou de suas organizações, priorizando-se os assentamentos da reforma agrária, as comunidades tradicionais indígenas e as comunidades quilombolas. A aquisição dos produtos da Agricultura Familiar poderá ser realizada por meio da Chamada Pública, dispensando-se, nesse caso, o procedimento licitatório.

A conexão entre a agricultura familiar e a alimentação escolar fundamenta-se nas diretrizes estabelecidas pela Lei $\mathrm{n}^{\circ}$ 11.947/2009, que dispõe sobre o atendimento da $\mathrm{AE}$, em especial no que tange: ao emprego da alimentação saudável e adequada, compreendendo o uso de alimentos variados, seguros, que respeitem a cultura, as tradições e os hábitos alimentares saudáveis; e ao apoio ao desenvolvimento sustentável, com incentivos para a aquisição de gêneros alimentícios diversificados, sazonais, produzidos em âmbito local e pela agricultura familiar (FNDE).

Apesar do PNAE prever estes diversos ganhos, na literatura e na observação da realidade do pequeno agricultor é possível identificar diversos desafios. Rios, Barbosa e Severino (2018), a partir de uma revisão sistemática da literatura, identificaram como fatores preponderantes relacionados às dificuldades enfrentadas pelos agricultores familiares, a falta de acesso aos editais, dificuldade de alcançar os mercados e distribuir as mercadorias. Sendo assim, verifica-se como oportuno o desenvolvimento de produtos que contribuam nesta perspectiva.

\subsection{A gestão de desenvolvimento de produtos}

Segundo Rozenfeld et al (2006), desenvolver produtos consiste em um conjunto de atividades por meio das quais busca-se, a partir das necessidades do mercado e das possibilidades e 
restrições existentes. Segundo os autores, o ambiente competitivo das organizações impõe um melhor planejamento e gestão no desenvolvimento dos produtos, já que cada vez mais os clientes estão exigentes, buscando soluções e produtos ou tecnologias que lhe satisfaçam. Desta forma, Rozenfeld et al (2006), descrevem que para uma gestão eficaz do desenvolvimento de produto é necessário ter um modelo unificado de Processo de Desenvolvimento do Produto (PDP) e divide-o em fases sendo conhecidas como pré desenvolvimento, fase do desenvolvimento e a fase do pós desenvolvimento. A Figura 1 mostra as fases do PDP.

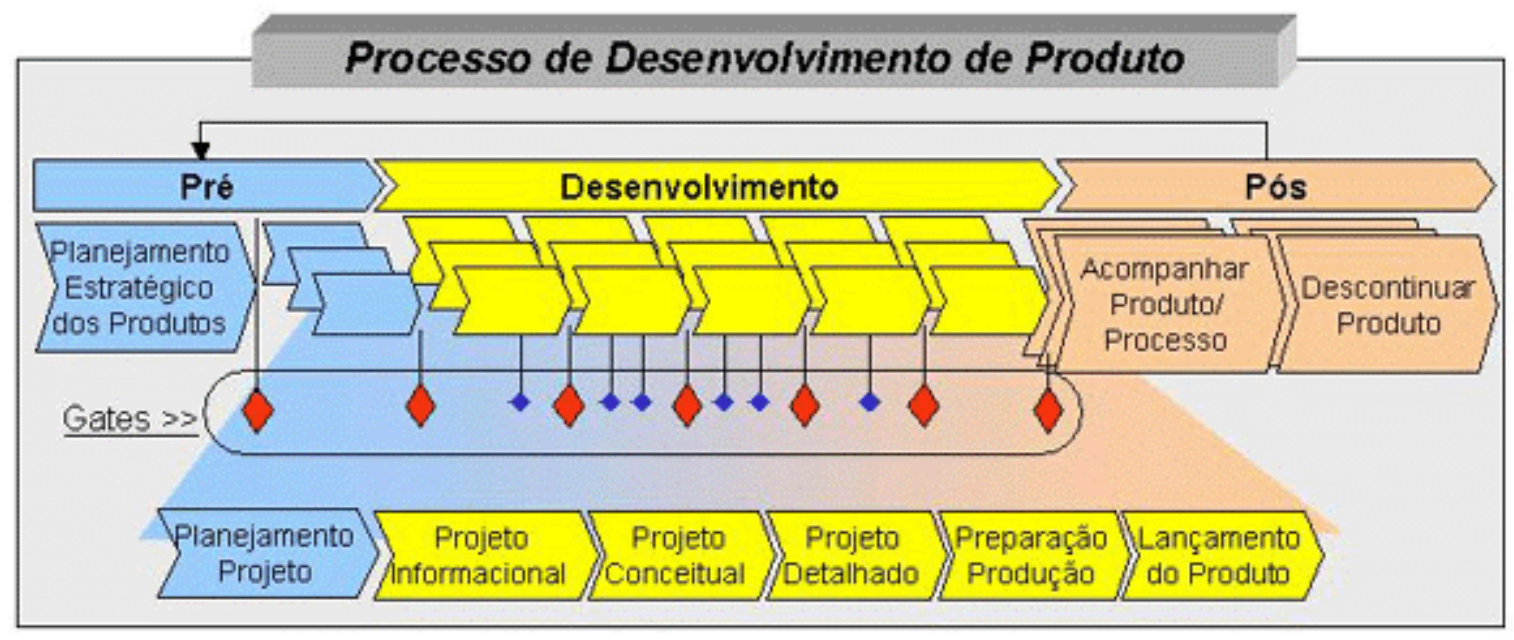

FIGURA 1 - Fases do PDP. Fonte: Rozenfeld et al (2006)

Dividir o processo de desenvolvimento de produtos entre etapas de trabalho e etapas de decisão assegura a ligação necessária entre objetivos, planejamento e execução (PAHL e BEITZ, 1996). Para obter o máximo do negócio deve-se usar um procedimento dividido em fases alternando pontos de verificação. Durante todo o processo do projeto, os resultados deverão ser confrontados com os objetivos estabelecidos para marketing e produção (ANDREASEN e HEIN, 1987).

Como a proposta deste artigo envolve apenas a fase do projeto conceitual, será dada maior ênfase na importância desta fase. No projeto conceitual, as atividades da equipe de projeto relacionam-se com a busca, criação, representação e seleção de soluções para o problema de projeto. No início da fase de projeto conceitual o produto é modelado funcionalmente e descrito de uma forma abstrata, independentemente de princípios físicos.

Do ponto de vista do desenvolvimento de produtos "Conceito" é o conjunto de benefícios adquiridos pelo consumidor. É a intenção global do produto ou serviço vistos da perspectiva 
do consumidor (SLACK, 1999). Assim, todo produto ou serviço está associado a um ou a vários conceitos. Uma caneta, um carro, uma televisão apresentam conceitos que muitas vezes não estão explícitos, mas podem ser identificados. Indivíduos diferentes podem associar diferentes conceitos num mesmo produto. Entretanto, deve existir um conjunto comum de conceitos associados ao produto que agradem um segmento específico de consumidores (IAROZINSKI NETO e FAVARETTO, 2005).

Os conceitos precisam ser desenvolvidos a ponto de permitirem a avaliação das tecnologias empregadas, a avaliação da arquitetura básica e em certo grau, a manufaturabilidade do produto. Podem ser representados através de rascunhos, fluxogramas, cálculos, protótipos, anotações, etc (BOLGENHAGEN, 2003).

Independente da forma como o conceito é representado, o ponto chave é possuir detalhes o suficiente para que a ideia de funcionalidade possa ser assegurada (ULLMANN, 1997).

Para Crawford e Di Benedito (2016), um conceito é uma expressão verbal e/ou prototípica que informa o que será mudado e o que o cliente provavelmente terá a ganhar (e perder). Para os autores, logo no início, as informações são bastante incompletas, mas quando comercializado o conceito estará completo. Tudo o que não significa ganho e perda para o consumidor alvo ainda é apenas uma ideia que precisa ser trabalhada.

A Figura 2 ilustra as informações principais na fase do projeto conceitual. Segundo Rozenfeld et al (2006), no modelamento funcional, a partir de uma análise das especificações-meta do produto e das funções inicialmente identificadas, o primeiro passo para a busca da estrutura das funções é a elaboração de uma descrição da função total, ou global do produto. Para os autores, a modelagem funcional auxilia a descrever os produtos em um nível mais abstrato, possibilitando a obtenção da estrutura de produto. Os modelos funcionais permitem que o produto seja representado por suas funcionalidades.

Existem três inputs requeridos pelo processo de criação do conceito do produto (CRAWFORD e DI BENEDITO, 2006). São eles:

- Forma: Trata-se do que é criado fisicamente ou, no caso de um serviço, da sequência das etapas ao longo das quais o serviço será criado.

- Tecnologia: Essa é a fonte por meio da qual a forma é obtida.

- Necessidade/Benefício: O produto terá valor apenas se oferecer algum benefício que o cliente considera necessário ou desejável. 


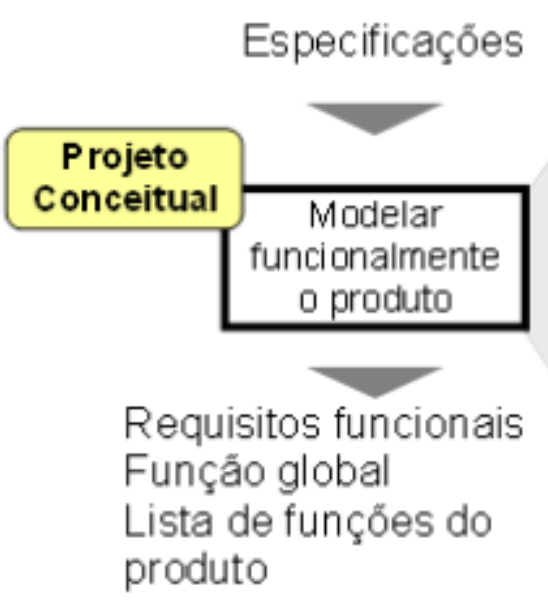

\section{Analisar as especificações}

meta do produto

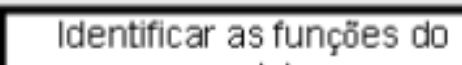

produto

Estabelecer a

funçăo global

\section{Requisitos funcionais \\ Funçẫo global produto}

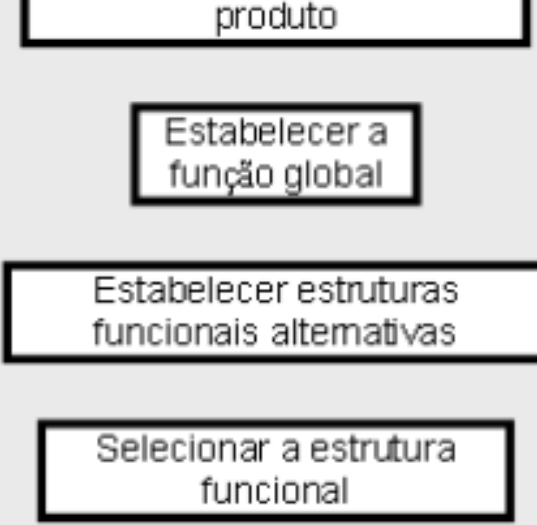

FIGURA 2 - A modelagem funcional do projeto conceitual. Fonte: Rozenfeld et al. (2006).

Segundo Crawford e Di Benedito (2016, p.103), “a tecnologia permite desenvolver uma forma que oferece um benefício". Na falta de qualquer um desses três fatores, não pode haver inovação de produto.

Sendo assim, para o problema de pesquisa em questão, é entendido como oportuno o desenvolvimento de uma tecnologia social em forma de programa computacional e/ou aplicativo para smartphones que auxiliem o pequeno agricultor a realizar uma melhor gestão da produção em relação a sua participação no PNAE.

\section{METODOLOGIA}

A coleta de dados foi concentrada em um grupo de agricultores familiares no Assentamento de Canudos nas cidades de Campestre de Goiás, Guapó e Palmeiras de Goiás no estado de Goiás. A pesquisa se deu inicialmente pela visita in loco por parte dos pesquisadores no local de estudo para planejamento, sendo seguida por outras visitas a fim de coletar dados, informações, dificuldades e as suas necessidades. Para isso foram realizadas entrevistas, além de observação direta para compreender melhor os desafios encontrados pelos agricultores em termos da participação no PNAE.

Para a modelagem funcional, por meio da representação da estrutura das funções do aplicativo, inicialmente foi necessário analisar as especificações-meta do aplicativo para compreender inicialmente o conceito do produto. Feito isto, a partir da coleta de dados 
durante as visitas e o levantamento das necessidades e dificuldades enfrentadas pelos assentados, o time do projeto realizou reuniões para a aplicação do método de brainstorming. Foram levantadas ideias e soluções que deveriam compor as funções técnicas do aplicativo e estas funções foram desdobradas conforme as informações levantadas nas entrevistas com a comunidade de agricultores.

Dentre os principais desafios foram identificados: o conhecimento quanto ao custo de produção de cada produto, identificar os editais em que a participação se torna mais viável e definir uma rota que reduza o custo de produção dos produtos. Sendo assim, em conjunto com a comunidade, definiu-se como prioridade o desenvolvimento de um programa computacional que auxilia os agricultores nestas dificuldades.

Em um último momento, em paralelo com a modelagem funcional, foram desenvolvidos modelos científicos para cada função. Para a Função 1 - Custos foi realizado, por meio de entrevistas, o levantamento dos elementos de custo de produção de todos os produtos fornecidos pela comunidade. Sendo assim, foi possível elaborar um modelo genérico em que cada produtor pudesse inserir os custos inerentes a sua forma de produzir. Para o modelo científico de custos, a modelagem foi realizada por meio de macros do Microsoft Excel. Para as demais funções, por meio de reunião com os agricultores, foram identificados os principais elementos que definem o critério de priorização do grupo. Assim, estes elementos foram: modelados a partir de Análise Envoltória de Dados (Data Envelopment Approach-DEA) por meio de macros do Microsoft Excel para a Função 2 - Decisão Edital; modelados a partir de Programação Linear Inteira Mista (PLIM) por meio de JuliaPRO para a Função 3 - Decisão

\section{Contrato e Funcão 4 - Decisão Roteamento.}

\section{RESULTADOS E DISCUSSÃO}

O público alvo inicial desta pesquisa que é o assentamento de Canudos teve sua origem em outubro de 1997 em homenagem à Comunidade Canudos na Bahia. Foi resultado da ocupação da fazenda Palmeiras (extensão de 12.757 hectares) e pertencente à família de Colemar Rezende - que foi presidente da União Democrática Ruralista nos anos 90 . O assentamento está localizado entre as cidades de Palmeiras de Goiás, Campestre de Goiás e Guapó. O nome do acampamento foi escolhido pelas próprias famílias após a ocupação da fazenda e definido como Canudos, pois estava próximo da data dos 100 anos do massacre de Canudos. É em 
homenagem à luta pública e à resistência das pessoas que estavam deixando a seca e iniciando uma nova forma de relacionamento entre as pessoas e o uso da terra.

$\mathrm{O}$ projeto que vem sendo realizado juntamente com esta comunidade deu a origem às especificações-meta do aplicativo, proposta de produto deste artigo. $\mathrm{O}$ aplicativo que é uma tecnologia social tem como especificações-meta auxiliar os agricultores familiares a tomarem decisões para participarem de chamadas do PNAE de forma rentável. Através da técnica de braistorming realizada pelo time deste projeto foram levantadas ideias com o intuito de desenvolver as funções técnicas do aplicativo, dando origem a Figura 3.

A concepção do produto basicamente consiste em um aplicativo que ao iniciar a tela, solicitará ao usuário um cadastro e em seguida buscará informações sobre chamadas abertas do PNAE num raio estabelecido pelo usuário. O usuário, neste caso o agricultor familiar, terá a partir deste momento um de seus problemas solucionados, já que a maioria dos agricultores não conseguem fazer uma pesquisa com sucesso das chamadas do PNAE a tempo hábil para envio das propostas. Logo em seguida, o aplicativo passará por 4 funções, conforme mostra a Figura 3 que mostra a modelagem funcional através da estrutura das funções e os seus desdobramentos a partir da função global do aplicativo.

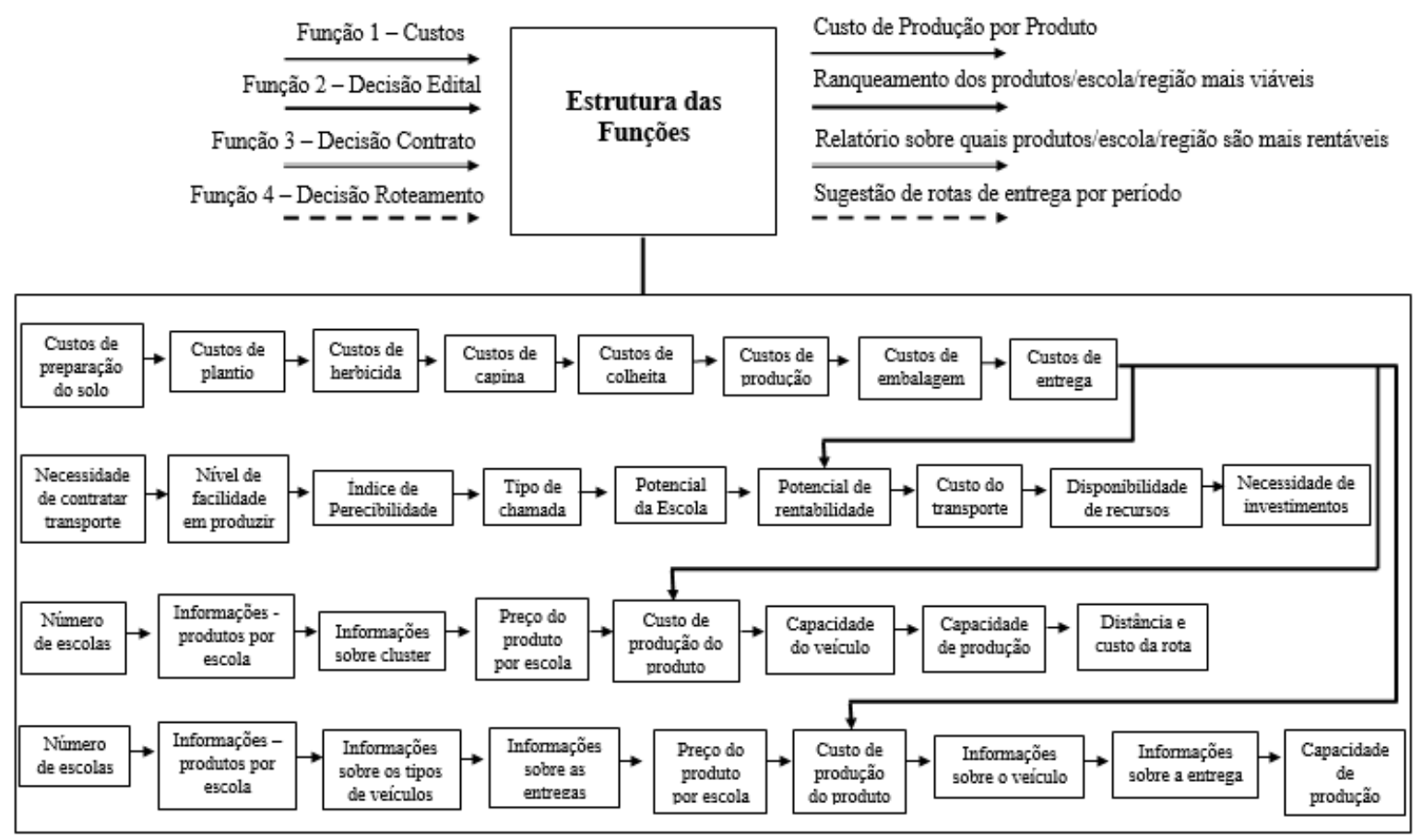

FIGURA 3 - Modelagem funcional do aplicativo. 
Pode-se observar na Figura 3 que cada função do aplicativo vai levar a uma informação diferente gerada pelo aplicativo e, o conjunto das funções ao final irá auxiliar o agricultor a tomar a melhor decisão.

A primeira função do aplicativo, será a Função 1 - Custo. Na primeira linha do desdobramento da estrutura das funções percebe-se que existem algumas informações em que o agricultor deverá inserir à medida que for passando de etapa. A primeira informação solicitada é sobre os custos de preparação do solo, onde poderão ser inseridas informações sobre maquinário, mão-de-obra, entre outros custos referentes à preparação. Em seguida, a segunda informação solicitada será sobre os custos de plantio e assim por diante, conforme mostra as setas de indicação. É importante ressaltar que a inserção exata das informações nesta função de custos levará a uma tomada de decisão eficaz, já que os desdobramentos das outras funções solicitam informações acerca da função custos, conforme indica as setas na Figura 3.

Em relação à segunda função, trata-se de um modelo de decisão para auxiliar o pequeno agricultor a tomar a decisão de em qual edital apresentar seu projeto de venda. Esta decisão se torna importante a medida os editais são publicados quase que concomitantemente, com duração de no máximo 20 dias. Por serem muito editais e o mesmo produto com preços diferentes para cada escola a tomada de decisão se torna complexa, além da incapacidade de apresentar propostas para todos os editais. Assim, a Funcão 2 - Decisão Edital, através de uma programação utilizando DEA é realizado o ranqueamento dos produtos/escola/região em que submeter um projeto de venda se torna mais viável (seja por rentabilidade ou por chances de ser o vencedor da concorrência). Após o processamento das informações é apresentado um relatório com o raqueamento com a indicação de quais editais deve ser priorizada a elaboração e a entrega dos projetos de venda.

A terceira função da tecnologia social que está sendo desenvolvida é a Função 3 - Decisão Contrato. Em função das regras de prioridade do PNAE, quando o agricultor apresentar seu projeto de venda podem ocorrer três situações: ser vencedor na íntegra, ser vencedor somente com alguns produtos ou não ser vencedor. A partir deste novo cenário, a solução apresenta pela Função 2 do aplicativo, pode não ter mais validade. Sendo assim, a partir dos resultados das candidaturas e agora inserindo restrições de capacidade de produção, os dados são processados a partir de um modelo de Programação Linear Inteira Mista (PLIM) de otimização de lucros, processado na linguagem JuliaPRO, para identificação dos contratos 
apresentados pelas escolas/municípios que devem ser assinados e o agricultor se comprometer com as entregas, por serem os mais lucrativos.

Por fim, na Função 4 - Decisão Roteamento são adicionados informações acerca da frequência de entrega de cada um dos produtos de cada uma das escolas. Destaca-se que normalmente estas informações são repassadas aos pequenos agricultores com aproximadamente 20 dias de antecedência. Desta forma, a partir dos dados, a partir de um modelo de Programação Linear Inteira Mista (PLIM) de minimização de custos, processado na linguagem JuliaPRO, é emitido um relatório com as datas e rotas de entrega dos alimentos do agricultor para as escolas.

Por meio deste modelo funcional, será possível dar sequência ao processo de desenvolvimento desta tecnologia social, permitindo que em um futuro próximo os pequenos agricultores possam tomar decisões mais assertivas sobre a sua participação no PNAE.

\section{CONCLUSÃO}

Por tratar-se de uma solução de transformação social genérica construída juntamente e por meio da interação com a comunidade de assentados, verifica-se um potencial de replicabilidade e uso por outras comunidades que vislumbram a partir da participação como fornecedores do PNAE aumentar a renda, melhorar a qualidade de vida, e garantir o exercício da cidadania. Desta forma, a proposta do projeto deste aplicativo é uma solução tecnológica inovadora e além disso, de caráter social que poderá contribuir na inclusão produtiva e social de comunidades rurais vulneráveis de todo o Brasil.

O projeto conceitual através da modelagem funcional do produto contribuiu na descrição das funções em um nível abstrato, permitindo formular as funções e os seus desdobramentos prevendo as dificuldades, além de solucionar possíveis problemas antecipadamente no uso do aplicativo. A formulação do conceito, mesmo que em um plano abstrato abre caminhos para soluções melhores, podendo levar a um resultado satisfatório na tomada de decisão ideal para os agricultores familiares.

\section{AGRADECIMENTOS}

Os autores deste artigo agradecem todos os membros da equipe das diferentes instituições envolvidas: Universidade Federal de Goiás (UFG), University of Strathclyde (UoS), 
Universidade de São Paulo (USP), Universidad Peruana de Ciências Aplicadas (UPC), Movimentos dos Trabalhadores Rurais Sem Terra (MST).

Também, agradece-se os órgãos que estão financiando a pesquisa: Fundação de Amparo à Pesquisa do Estado de Goiás (FAPEG), Conselho Nacional de Desenvolvimento Científico e Tecnológico (CNPq) e o British Council através do Newton Fund.

\section{REFERÊNCIAS}

ANDREASEN, M.M.; HEIN, L. Integrated Product Development. IFS (Publications) Ltd / Springer-Verlag, London, 1987.

BOLGENHAGEN, N.J. O processo de desenvolvimento de produtos: proposição de um modelo de gestão e organização. Dissertação de mestrado. Universidade Federal do Rio Grande do Sul. Porto Alegre-RS. Brasil, 2003.

BRASIL. LEI N 11.326, DE 24 DE JULHO DE 2006. Estabelece as diretrizes para a formulação da Política Nacional da Agricultura Familiar e Empreendimentos Familiares Rurais. Diário Oficial da União. Brasília-DF. Disponível em: https://legis.senado.leg.br/sdleg-getter/documento?dm=4080268\&disposition=inline Acesso em: 21 de junho de 2019.

BRASIL. LEI No 11.947, DE 16 DE JUNHO DE 2009. Dispõe sobre o atendimento da alimentação escolar e do Programa Dinheiro Direto na Escola aos alunos da educação básica. Diário Oficial da União. Brasília-DF. Disponível em: https://legis.senado.leg.br/sdleg-getter/documento?dm=3565839 Acesso em: 21 de junho de 2019.

CENSO AGROPECUÁRIO. Censo Agropecuário 2017. Disponível em: https://censos.ibge.gov.br/agro/2017/ Acesso em: 14 de junho de 2019.

CRAWFORD, M.; DI BENEDETTO, A. Gestão de Novos Produtos. 11 ed. Porto Alegre: AMGH Editora Ltda, 2016.

FUNDO NACIONAL DE DESENVOLVIMENTO DA EDUCAÇÃO - FNDE. Sobre o PNAE. Disponível em: https://www.fnde.gov.br/ Acesso em: 14 de junho de 2019.

IAROZINSKI NETO, A.; FAVARETTO, F. Projeto conceitual: o projeto da "forma" do produto. V CBGDP Curitiba-PR. Brasil, 2005.

MINISTÉRIO DA AGRICULTURA, PECUÁRIA E ABASTECIMENTO - MDA. Secretaria de Agricultura Familiar e Cooperativismo. O que é a agricultura familiar. Disponível em: http://www.mda.gov.br/ Acesso em: 14 de junho de 2019 .

PAHL, G.; BEITZ, W. Enginnerin Design - A systematic approach. Springer-Verlag London Limited, London, 1996.

RIOS, M. L. M. R; BARBOSA, L. Q.; SEVERINO, M. R. Estudo sobre desafios dos agricultores familiares na participação no Programa Nacional de Alimentação Escolar (PNAE) - uma revisão de literatura. In: Anais do XXXVIII Encontro Nacional de Engenharia de Produção. Maceió. ABEPRO, Rio de Janeiro: 2018.

ROZENFELD, H.; FORCELLINI, F. A.; AMARAL, D. C.; et al. Gestão de Desenvolvimento de Produto: uma referência para a melhoria do processo. 1 ed. São Paulo: Saraiva, 2006.

SLACK, Nigel. Administração da produção. São Paulo: Atlas, 1999. 526 p. ISBN 85-224-2171-4

UllmAN, D.G. The Mechanical Design Process. McGraw-Hill Companies, Inc. Singapore, 1997. 